\title{
ROLE OF FNAC IN PREDICTING MALIGNANCY IN BREAST LESIONS
}

\author{
Ambedkar Raj Kulandai Velu1, Mourouguessine Vimal², Anand S. Patil33, E. M. K. S. Jhansi Rani ${ }^{4}$ \\ ${ }^{1}$ Professor, Department of Pathology, Chennai Medical College Hospital and Research Centre, Trichy, Tamilnadu. \\ ${ }^{2}$ Assistant Professor, Department of Pathology, Sri Manakula Vinayagar Medical College and Hospital, Kalitheerthalkuppam, \\ Madagadipet, Puducherry. \\ ${ }^{3}$ Associate Professor, Department of Pathology, Sri Manakula Vinayagar Medical College and Hospital, Kalitheerthalkuppam, \\ Madagadipet, Puducherry. \\ ${ }^{4}$ Student, Department of Pathology, Sri Manakula Vinayagar Medical College and Hospital, Kalitheerthalkuppam, Madagadipet, \\ Puducherry.
}

\section{ABSTRACT}

\section{CONTEXT}

FNAC is the initial first line of investigation in evaluating breast lesions because of its reliability, rapidity and cost effectiveness, even in the present era of open biopsy.

\section{AIM}

To evaluate the role of FNAC in diagnosing malignancy in breast lesions and to compare it with the Gold standard Histopathology.

\section{MATERIALS AND METHODS}

Patients with breast lesions, evaluated by FNAC and had subsequent histopathological examination were studied to correlate the diagnoses. Statistical analysis was done to find sensitivity, specificity and positive predictive value and negative predictive value of FNAC test in diagnosing malignant breast lesions.

\section{RESULTS}

Among 158 total FNAC cases, 105 had subsequent histopathological followup. Out of 74 cytologically benign cases, 69 were confirmed as benign, 5 turned malignant. Out of 4 cytologically atypical cases, one turned benign and 3 malignant. Out of 27 cytologically malignant cases, 26 were malignant and one turned benign. FNAC had a sensitivity of $85.29 \%$, specificity of $97.18 \%$, positive predictive value of $93.55 \%$ and negative predictive value of $93.24 \%$.

\section{CONCLUSION}

Though FNAC has its own flaw, it still remains as a diagnostic tool in the preoperative evaluation of breast lesions in picking up malignant breast lesions as comparable to histopathology.

\section{KEYWORDS}

Breast Lesions, Fine Needle Aspiration Cytology, Histopathology.

HOW TO CITE THIS ARTICLE: Ambedkar Raj Kulandai Velu, Mourouguessine Vimal, Anand S. Patil, E. M. K. S. Jhansi Rani. "Role of FNAC in Predicting Malignancy in Breast Lesions." Journal of Evolution of Medical and Dental Sciences 2015; Vol. 4, Issue 101, December 17; Page: 16599-16601, DOI: 10.14260/jemds/2015/2475

\section{INTRODUCTION}

Martin and Ellis in 1930 introduced the technique of FNAC intitially for sampling cervical lymph nodes.(1) Later it became widespread first line of investigation for evaluating mass lesions, especially for organs like breast and thyroid. Many institutions in the Western countries have stopped FNAC and shifted to routine core biopsy procedure for diagnosing breast lesions.(2)

But in many developing countries FNAC is still the initial first line of investigation in evaluating and managing the breast lesions because of its more reliability, rapidity, cost

Financial or Other, Competing Interest: None.

Submission 25-11-2015, Peer Review 26-11-2015,

Acceptance 10-12-2015, Published 15-12-2015.

Corresponding Author:

Dr. Mourouguessine Vimal

No. 21, Narmatha Street,

Vasantha Nagar,

Muthiyalpet, Puducherry-605003.

E-mail:drvimalm@gmail.com

DOI:10.14260/jemds/2015/2475 effectiveness and minimal complications. FNAC has its own flaw in differentiating benign and malignant lesions, especially when there is a morphological overlap and paucity of specimen sampling.(3) and also rare untoward complications like haematoma and pneumothorax formation.

\section{AIMS AND OBJECTIVES}

The aim of this study was to evaluate the role of FNAC in diagnosing malignancy in breast lesions in the present era of open biopsy by classifying the spectrum of breast lesions diagnosed by FNAC and to compare it with the Gold standard Histopathology. An attempt was also made to answer the question whether open biopsy techniques can completely replace FNAC and to explore the possible reasons for False positive and False negative results in FNAC.

\section{MATERIALS AND METHODS}

This is a retrospective study done on patients who presented with breast lesions and had initial evaluation with FNAC. The breast lesions diagnosed by FNAC were interpreted and categorized according to risk of developing cancer as benign, 
suspicious of malignancy and malignancy. Histopathological examination was done on excision and tru-cut biopsy specimens and an attempt was made to correlate FNAC and histopathological diagnosis. Statistical analysis was done to find the Sensitivity, Specificity and Positive predictive value and Negative predictive value of FNAC test in diagnosing malignant breast lesions were assessed.

\section{RESULTS}

Out of total 158 cases of FNAC 122 cases were given diagnosis of benign breast diseases, 6 cases as suspicious of malignancy and 30 cases as malignancy. Among 158 total FNAC cases, 105 cases had a subsequent histopathological followup. The correlation of FNAC with histopathological diagnosis is shown in Table 1. Out of 74 cytological benign cases 69 were confirmed as benign on histopathology, but 5 turned out to be malignant. Out of 4 cytological atypical cases, one was benign and 3 were malignant. Out of 27 cytological malignant cases, 26 were confirmed as malignant, but one turned out as benign. Hence, the total numbers of histopathologically confirmed benign cases were $71(67.62 \%)$ and malignant cases were $34(32.38 \%)$ (Table 2).

Table 3 summarises the data of FNAC as a diagnostic test and Table 4 compares the sensitivity, specificity, positive predictive value and negative predictive value of the present study with similar other studies. In short the present study shows that FNAC has a sensitivity of $85.29 \%$, specificity of 97.18, positive predictive value of 93.55 and negative predictive value of 93.24 and is quite comparable with similar other studies.

\section{DISCUSSION}

A multidisciplinary team approach is usually recommended for evaluating breast lesions prior to definitive treatment, because of the need to differentiate benign and malignant lesions and even to differentiate pathological breast mass from normal variation in breast parenchyma. In many developing countries, fine needle aspiration cytology remains as a first line diagnostic technique for evaluating palpable breast lesions.

The present study accounts for more number of benign cases than malignant cases similar to other studies. This can be attributed to increasing awareness among the patients and good followup. (Table 1) Out of total 122 benign cases, Fibroadenoma is the commonest one ( 68 cases) accounting for $55.7 \%$, which is similar to other studies. $(4,5)$ Out of total 30 confirmed malignant cases, invasive ductal carcinoma is the commonest one (26 cases) accounting for $88.6 \%$, which is similar to Domínguez et al.(4) As invasive ductal carcinoma is the overall commonest malignant lesion. Generally, it is not preferred to subclassify malignant lesions in FNAC, unless it is needed in special circumstances.
In this study more number of cytologically benign cases were seen in the age group of 20-40 years and malignant lesions were commonly seen in the 40-60 years age group, which is similar to other studies. ${ }^{(6,7)}$ But it has to be kept in mind that both entities can occur in all age groups and every case should be evaluated by its own considerations. Since for most of the benign lesions, conservative management is the treatment of choice, careful correlation has to be made with radiological, FNAC and histopathological findings. ${ }^{(8)}$

During reporting of the FNAC cases caution has to be taken for making over-diagnosis. Hence cases of fibroadenoma, fibrocystic change disease, benign proliferative disease and phyllodes tumors were considered as benign category and the uncertain cases were designated as suspicious of malignancy category and cases with frank malignant features were graded as malignant.

The diagnostic failure of the FNAC procedure in some cases can be attributed to unsatisfactory and nonrepresentative aspirates, especially in smaller lesions and in tumours with low cellularity like scirrhous carcinoma. These pitfalls can be overcome by performing the FNAC under radiological guidance. ${ }^{(9)}$ or by using 27 -gauge needle in the periphery of the lesion. Using more trained personnel and adopting radiologically guided FNACs can yield more satisfactory and representative aspirates and can reduce the false negative results in FNAC.

Hypercellular lesions like cellular fibroadenoma, proliferative breast disease, phyllodes tumour and post radiation induced atypical changes can have findings like nucleomegaly with mild pleomorphism and presence of nucleoli, which may sometimes erroneously report malignancy in benign lesions. These false positive FNAC results can be reduced by considering biopsy in such cases, especially when the aspirate yields poor cellularity shows presence of bare nuclei and lesser degree of atypia.(10)

Tabbara et al.(11) recommended a standardized approach for reporting FNAC in breast lesions into benign, atypical/ indeterminate, suspicious/probably malignant, malignant and unsatisfactory. This uniform approach can address the controversies related to breast FNAC to some extent.

\section{CONCLUSION}

FNAC is less painful, cost effective, less time consuming simple procedure than biopsy. FNAC still remains as a diagnostic tool in the preoperative evaluation of breast lesions, especially in developing countries with limited resources. Though FNAC has its own flaw, it has a higher sensitivity, specificity, positive predictive value and negative predictive value in picking up malignant breast lesions as comparable to histopathology.

\begin{tabular}{|c|c|c|c|c|}
\hline \multirow{2}{*}{$\begin{array}{c}\text { FNAC Category of } \\
\text { Breast Lesion }\end{array}$} & \multirow{2}{*}{$\begin{array}{c}\text { Number of FNAC } \\
\text { Cases }\end{array}$} & $\begin{array}{c}\text { Cases with } \\
\text { Histopathological } \\
\text { Follow up }\end{array}$ & Henign & Malignant \\
\cline { 3 - 5 } & 122 & 74 & 69 & 5 \\
\hline Benign & 6 & 4 & 1 & 3 \\
\hline Suspicious of malignancy & 30 & 27 & 1 & 26 \\
\hline Malignant & $\mathbf{1 5 8}$ & $\mathbf{1 0 5}$ & $\mathbf{7 1}$ & $\mathbf{3 4}$ \\
\hline Total & \multicolumn{4}{|r}{} \\
\hline \multicolumn{2}{r}{ Table 1: Histopathological correlation of FNAC Cases } \\
\hline
\end{tabular}




\begin{tabular}{|c|c|c|c|}
\hline Study & Benign (\%) & Malignant (\%) & Total \\
\hline Present study & $71(67.62)$ & $34(32.38)$ & 105 \\
\hline Sankaye et al.(12) & $31(40.78)$ & $45(59.21)$ & 76 \\
\hline Mohammed et al. & $61(65.59)$ & $32(34.4)$ & 93 \\
\hline Kim et al.(13) & $153(62.19)$ & $93(37.8)$ & 246 \\
\hline Park and Ham(14) & $107(54.04)$ & $91(45.95)$ & 198 \\
\hline Choi et al.(15). & $266(58.2)$ & 191 (41.79) & 457 \\
\hline
\end{tabular}

\begin{tabular}{|c|c|c|c|}
\hline \multirow{2}{*}{ FNAC } & \multicolumn{2}{|c|}{ Histopathology } & \multirow{2}{*}{ Total } \\
\hline & Malignant & Benign & \\
\hline Malignant & 29 (True Positive) & 2 (False Positive) & 31 \\
\hline Benign & 5 (False Negative) & 69 (True Negative) & 74 \\
\hline Total & 34 & 71 & 105 \\
\hline
\end{tabular}

\begin{tabular}{|c|c|c|c|c|}
\hline & Sensitivity & Specificity & $\begin{array}{c}\text { Positive Predictive } \\
\text { Value }\end{array}$ & $\begin{array}{c}\text { Negative Predictive } \\
\text { Value }\end{array}$ \\
\hline Present study & 85.29 & 97.18 & 93.55 & 93.24 \\
\hline Sankaye et al.(12) & 88.37 & 96.42 & 97.43 & 84.37 \\
\hline Choi et al.(15) & 77.70 & 99.20 & 98.40 & 88.00 \\
\hline Park and Ham.(14) & 76.90 & 91.60 & - & - \\
\hline Kim et al.(13) & 94.59 & 87.91 & 79.54 & 97.03 \\
\hline \multicolumn{2}{|r|}{ Table 4: Comparison of Statistical significance of FNAC in present study with other studies } \\
\hline
\end{tabular}

\section{REFERENCES}

1. Litherland JC. Should Fine Needle Aspiration Cytology in Breast Assessment Be Abandoned? Clin Radiol. 2002 Feb 1;57(2):81-4.

2. Yu Y-H, Wei W, Liu J-L. Diagnostic value of fine-needle aspiration biopsy for breast mass: a systematic review and meta-analysis. BMC Cancer. 2012 Jan 25;12(1):41.

3. Mendoza P, Lacambra M, Tan P-H, et al. Fine needle aspiration cytology of the breast: the non-malignant categories. Pathol Res Int. 2011;2011:547-580.

4. Domínguez F, Riera JR, Tojo S, et al. Fine needle aspiration of breast masses. An analysis of 1,398 patients in a community hospital. Acta Cytol. 1997 Apr;41(2):341-7.

5. Tiwari M. Role of fine needle aspiration cytology in diagnosis of breast lumps. Kathmandu Univ Med J KUMJ. 2007 Jun;5(2):215-7.

6. MacIntosh RF, Merrimen JL, Barnes PJ. Application of the probabilistic approach to reporting breast fine needle aspiration in males. Acta Cytol. 2008 0ct;52(5):530-4.

7. Rocha PD, Nadkarni NS, Menezes S. Fine needle aspiration biopsy of breast lesions and histopathologic correlation. An analysis of 837 cases in four years. Acta Cytol. 1997 Jun;41(3):705-12.

8. Shah SAA, Pervez SN, Javed K. Diagnostic performance of Fine Needle Aspiration Cytology (FNAC) in the diagnosis of breast lumps. J Ayub Med Coll Abbottabad. 2013;25(1-2):46-8.
9. Parker SH, Stavros AT, Dennis MA. Needle biopsy techniques. Radiol Clin North Am. 1995 Nov; 33 (6): 1171-86.

10. Challa VR, Yale Guru BG, Rangappa P, et al. Cytological and pathological correlation of FNAC in assessing breast lumps and axillary lymph node swellings in a Public Sector Hospital in India. Pathol Res Int. 2013;2013:695-024.

11. Tabbara SO, Frost AR, Stoler MH, et al. Changing trends in breast fine-needle aspiration: results of the Papanicolaou Society of Cytopathology Survey. Diagn Cytopathol. 2000;22(2):126-30.

12. Sankaye SB, Dongre SD. Cytological study of palpable breast lumps presenting in an Indian rural setup. Indian J Med Paediatr Oncol Off J Indian Soc Med Paediatr Oncol. 2014 Apr;35(2):159-64.

13. Kim A, Lee J, Choi JS, et al. Fine needle aspiration cytology of the breast. Experience at an outpatient breast clinic. Acta Cytol. 2000 Jun;44(3):361-7.

14. Park IA, Ham EK. Fine needle aspiration cytology of palpable breast lesions. Histologic subtype in false negative cases. Acta Cytol. 1997 Aug;41(4):1131-8.

15. Choi YD, Choi YH, Lee J-H, Nam JH, Juhng S-W, Choi C. Analysis of fine needle aspiration cytology of the breast: a review of 1,297 cases and correlation with histologic diagnoses. Acta Cytol. 2004 Dec;48(6):801-6. 